\title{
Hemodynamic Changes during Hepatic Vascular Exclusion: Use of Intraoperative Transesophageal Echocardiography a Case Series
}

\author{
Franco Marinangeli, Alessandra Ciccozzi, Chiara Angeletti, Cristiana Guetti, \\ Tommaso Aloisio, Antonella Paladini, and Giustino Varrassi
}

Department of Anaesthesiology and Pain Management, University of L'Aquila, 67100 L'Aquila, Italy

Correspondence should be addressed to Chiara Angeletti, chiara.angeletti@gmail.com

Received 15 May 2011; Accepted 22 June 2011

Academic Editors: Y. Mehta and C. Motamed

Copyright (C) 2011 Franco Marinangeli et al. This is an open access article distributed under the Creative Commons Attribution License, which permits unrestricted use, distribution, and reproduction in any medium, provided the original work is properly cited.

\begin{abstract}
The aim of this clinical observation was to compare intraoperative transesophageal echocardiography (TEE) and pulmonary artery catheterization (PAC) during hepatic vascular exclusion (HEV). Five non-cirrhotic patients to undergo HVE for major liver resection have been observed. Hemodynamic parameters: pulmonary arterial wedge pressure (PCWP), cardiac index (CI), cardiac output (CO), and systemic vascular resistance (SVR) have been monitored by PAC. Left ventricular end-diastolic area (LVEDA), left ventricular end-systolic area (LVESA), left ventricular end-diastolic pressure (LVEDP), cardiac index (CI), cardiac output (CO), and fractional area changes (FAC) have been monitored by TEE. Hemodynamic variables were assessed before clamping $\left(T_{0}\right)$, at 5 and 30 minutes after clamping $\left(T_{1}, T_{2}\right)$ and 15 minutes after unclamping $\left(T_{3}\right)$. No significant difference between PCWP and LVEDP was found. LVEDP significantly decreased at $T_{1}$ and $T_{2}$ compared to $T_{0}(P<0.001)$; PCWP showed the same trend. A correlation was found between SV and $\operatorname{LVEDP}\left(R^{2}=0.755, P<0.001\right)$ as well as CI $\left(R^{2}=0.630, P<0.001\right)$. Data confirm that intraoperative TEE may be a reliable method for hemodynamic monitoring during major liver resections.
\end{abstract}

\section{Introduction}

Major liver resection requires Hepatic Vascular Exclusion (HVE), a condition which is obtained by clamping portal triad and occluding inferior vena cava below and above the liver. This procedure completely isolates the liver and retrohepatic vena cava from the circulation, thus reducing the risk of massive haemorrhage and air embolism. During HVE, Mean Arterial Pressure (MAP) is maintained by a marked increase in SVR, which is a consequence of an increased secretion of vasopressin, norepinephrine, and epinephrine [1].

Invasive hemodynamic monitoring is a fundamental part of surgical procedure, as marked hemodynamic changes occur during major liver resection. Nowadays, PAC represents the most reliable technique for hemodynamic monitoring; nevertheless, TEE is becoming increasingly common during major noncardiac surgery. TEE allows to rapidly visualize left ventricular dimensions and function. The main purpose of this study was to assess intraoperative
TEE as a reliable system for hemodynamic monitoring compared to the pulmonary artery catheterization during HVE. Hemodynamic parameters have been measured by PAC and TEE, and the results, with particular regard to preload indices, have been compared.

\section{Methods}

Five consecutive patients undergoing major liver resection were studied according to a protocol approved by the committee on human research of the San Salvatore Hospital in L'Aquila, Italy. Written, informed consent was obtained by patients before surgery. Patients suffering from cirrhosis, chronic hepatitis, or other causes of portal hypertension, impaired renal function, defined as serum creatinine concentration $>120 \mathrm{~mol} / \mathrm{L}$, history of cardiac dysfunction, including cardiac arrhythmias, clinical history of congestive heart failure, preexisting valvular disease, preexisting severe left ventricular diastolic and/or systolic dysfunction, aortic 
aneurysm, and oesophageal diseases precluding TEE examination, were excluded from the study. Patients were premedicated with hydroxyzine $2 \mathrm{mg} / \mathrm{kg}$ orally, at $12 \mathrm{~h}$ and $1 \mathrm{~h}$ before surgery. In the operating room standard monitoring was set up and general anaesthesia was induced with propofol 1.5$2.5 \mathrm{mg} / \mathrm{Kg}$ and sufentanil administered via Target Controlled Infusion (TCI) to achieve $0.3-0.4 \mathrm{ng} / \mathrm{mL}$ concentration. Muscular relaxation was induced with atracurium $0.3-$ $0.5 \mathrm{mg} / \mathrm{Kg}$, iv, followed by a continuous infusion of $11-$ $13 \mathrm{mcg} / \mathrm{kg} / \mathrm{min}$. Anaesthesia was maintained with sufentanil infused via TCA to achieve a concentration of $0.15-$ $0.6 \mathrm{ng} / \mathrm{mL}$. All patients were artificially ventilated with a mixture of $\mathrm{O}_{2}$ : air $(1: 1)$ using low gas flow in a circle absorber system added with isoflurane $1.15-2 \%$ to maintain bispectral index (BIS) between 40 and 60. Mechanical ventilation was adjusted to maintain End Tidal $\mathrm{CO}_{2}\left(\mathrm{ETCO}_{2}\right)$ between 30 and $35 \mathrm{mmHg}$. Normothermia was achieved by forced-air warming, to maintain nasopharyngeal and pulmonary artery temperature around $36.5^{\circ} \mathrm{C}$. Thromboembolism prophylaxis was obtained by an intermittent pneumatic compression device. An arterial line was placed in the left radial artery and an 8.5 French percutaneous introducer was inserted in the right internal jugular vein to ensure pulmonary artery catheterization. Transoesophageal doppler probe was introduced after the pulmonary artery catheter had been inserted. The probe was positioned in order to obtain a transgastric mid-papillary short axis view of the left ventricular area. The probe was manipulated and rotated on its long axis until an adequate signal was obtained. The following hemodynamic parameters were monitored: Heart Rate (HR), Systolic, Diastolic and Mean Arterial Pressure (SAP, DAP, MAP), Stroke Volume (SV) (calculated as CO/HR*1000). Measured by PAC: Central Venous Pressure $\left(\mathrm{CVP}_{(\mathrm{PAC})}\right)$, Pulmonary Capillary Wedge Pressure $\left(\mathrm{PCWP}_{(\mathrm{PAC})}\right)$, Cardiac Output $\left(\mathrm{CO}_{(\mathrm{PAC})}\right)$, and Systemic Vascular Resistance $\left(\mathrm{SVR}_{(\mathrm{PAC})}\right)$. The following parameters were measured by TEE: Left Ventricular End-Diastolic Area $\left(\operatorname{LVEDA}_{(\mathrm{TEE})}\right)$, Left Ventricular End-Systolic Area LVESA $_{(\mathrm{TEE})}$, by tracing endocardial border including papillary muscles), Central Venous Pressure $\left(\mathrm{CVP}_{(\mathrm{TEE})}\right)$ (calculated as inferior vena cava diameter, instead of IVC collapsibility index), Left Ventricular EndDiastolic Pressure $\left(\operatorname{LVEDP}_{(\mathrm{TEE})}\right)$, Cardiac Index $\left(\mathrm{CI}_{(\mathrm{TEE})}\right)$, Cardiac Output $\left(\mathrm{CO}_{(\mathrm{TEE})}\right)$, and Fractional Area Contraction $\left(\mathrm{FAC}_{(\mathrm{TEE})}\right)$, an estimate of ejection fraction, calculated as LVEDA-LVESA/LVEDA expressed in percentage. Hemodynamic variables were assessed before clamping $\left(T_{0}\right)$, at times 5 and 30 minutes after clamping ( $T_{1}$ and $T_{2}$ resp.) and finally at 15 minutes after unclamping $\left(T_{3}\right)$. Hypovolemia was defined as LVEDA $<20 \mathrm{~cm}^{2}$, LVEDP $<8 \mathrm{mmHg}$, and PCWP $<10 \mathrm{mmHg}$ and was treated with fluids infusion until the values were normalized. Homologous packed red blood cells were transfused in order to maintain hematocrit $>30 \%$ and haemoglobin $>8 \mathrm{gr} / \mathrm{dL}$. Hypotension, defined as MAP $<60 \mathrm{mmHg}$ was treated with infusion of noradrenaline $0.01-$ $0.1 \mathrm{mcg} / \mathrm{kg} / \mathrm{min}$.

Hemodynamic measurements have been averaged and expressed as mean \pm SD. Analysis of variance for repeatedmeasures (ANOVA) Holm-Sidak method, Turkey test, and least significant difference test have been used for statistical
TABLE 1: Clinical data and intraoperative procedures in 5 patients undergoing elective liver resection by HVE.

\begin{tabular}{lc}
\hline Variable & Data $(n=5)$ \\
\hline Age (years) & $63 \pm 7.9$ \\
Sex & M/F: $3 / 2$ \\
Weight $(\mathrm{kg})$ & $65.6 \pm 13.9$ \\
ASA I-II-III & $1-3-1$ \\
Colloid infusion after clamping (mL) & $200 \pm 273.8$ \\
Blood Transfusions & 5 units/2 patients \\
$\quad$ Central hepatectomy & 3 units \\
$\quad$ Right hepatectomy & 2 units \\
Liver ischemia (min) & $57 \pm 10.3$ \\
\hline
\end{tabular}

Data are presented as means $\pm \mathrm{SD}$.

analysis. Paired $t$-test was used to evaluate the statistical difference between paired groups. $P$ values lower than 0.05 were considered statistically significant. Linear regression was used to examine the relationship between SV and LVEDP as well as CI and LVEDP.

\section{Results}

Clinical data of the five patients and intraoperative procedures are shown in Table 1. Hemodynamic findings recorded during HVE by standard monitoring, TEE and PAC, are summarized in Tables 2, 3, and 4, respectively. During HVE, MAP was maintained above $60 \mathrm{mmHg}$ without vasoconstrictors; colloid infusion was performed in one patient. Blood was transfused in one patient during HVE. After unclamping, SAP, DAP, and MAP returned to values not significantly lower than $T_{0}$. During HVE, HR significantly increased at $T_{1}$ and $T_{2}$ compared to $T_{0}(P<0.001)$; after unclamping $\left(T_{3}\right)$ HR decreased to baseline values. SVR significantly increased from $T_{0}$ to $T_{1}$, reached a plateau during HVE, and decreased to a lower value than baseline at $T_{3}(P=0.004)$. As for $\mathrm{CI}$ and $\mathrm{CO}$, both parameters significantly decreased $(P<0.001)$ during $\operatorname{HVE}\left(T_{1}-T_{2}\right)$, but increased to higher values than baseline after unclamping. No significant differences were found between CI, CO, and CVP measurements performed either by TEE and PAC. LV end-diastolic area (LVEDA), LV end-systolic area (LVESA), and FAC significantly decreased after clamping as well as during HVE (Figure 1); all parameters returned to their initials levels after unclamping. Pulmonary Capillary Wedge Pressure $\left(\mathrm{PCWP}_{(\mathrm{PAC})}\right)$ and Left Ventricular EndDiastolic Pressure (LVEDP $(\mathrm{TEE})$ ) followed the same trend, with a significant decrease from $T_{0}$ (before HVE) to $T_{1^{-}}$$T_{2}$ (during HVE) and a return to levels not different from baseline after unclamping (Figure 2). No statistical difference was observed between mean Pulmonary Capillary Wedge Pressure $\left(\mathrm{PCWP}_{(\mathrm{PAC})}\right)$ and Left Ventricular End-Diastolic Pressure $\left(\operatorname{LVEDP}_{(\mathrm{TEE})}\right)$. As for the markers of preload, linear regression analysis showed a significant correlation between Stroke Volume (SV) and Left Ventricular End-Diastolic Pressure $\left(\operatorname{LVEDP}_{(\mathrm{TEE})}\right)\left(r=0.869, r^{2}=0.755, P<0.001\right)$ and Cardiac Index $\left(\mathrm{CI}_{(\mathrm{TEE})}\right)\left(r=0.794, r^{2}=0.630, P<\right.$ $0.001)$ ) (Figures 3 and 4). 
TABLE 2: Hemodynamic parameters during hepatic vascular exclusion $(n=5)$.

\begin{tabular}{|c|c|c|c|c|}
\hline Parameter & $T_{0}$ & $T_{1}$ & $T_{2}$ & $T_{3}$ \\
\hline HR (bpm) & $66 \pm 9.4$ & $91 \pm 8.4^{*}$ & $99 \pm 8.5^{*}$ & $67 \pm 8.6$ \\
\hline MAP (mmHg) & $76.2 \pm 12.3$ & $69.2 \pm 19$ & $60 \pm 8$ & $63,4 \pm 10$ \\
\hline $\mathrm{SAP}(\mathrm{mmHg})$ & $107 \pm 12.7$ & $96 \pm 15.3$ & $90.2 \pm 5.9$ & $92.8 \pm 11.7$ \\
\hline DAP (mmHg) & $60.6 \pm 13.2$ & $56.4 \pm 20.2$ & $45.2 \pm 8.9$ & $49.2 \pm 8.8$ \\
\hline $\mathrm{SV}(\mathrm{mL} / \mathrm{bpm})$ & $76.2 \pm 17.8$ & $38.8 \pm 7^{*}$ & $33.4 \pm 10.4^{*}$ & $80.6 \pm 18$ \\
\hline SVR (dyne $\mathrm{s}^{-1} \mathrm{~cm}^{-5}$ ) & $1209 \pm 258$ & $1556 \pm 323.4^{\circ}$ & $1795 \pm 462^{\circ}$ & $950 \pm 152^{\circ}$ \\
\hline
\end{tabular}

Data are presented as means \pm SD; Heart Rate (HR), Mean Arterial Pressure (MAP). Systolic arterial pressure (SAP), Diastolic arterial pressure (DAP), Stroke Volume (SV), Systemic Vascular Resistance (SVR). $\left({ }^{*} P<0.001\right.$ versus $T_{0} ;{ }^{\circ} P=0.004$ versus $T_{0} ;{ }^{\bullet} P \leq 0.05$ versus $T_{0}$ ).

TABLE 3: Parameters measured by TEE during hepatic vascular exclusion $(n=5)$.

\begin{tabular}{lcccc}
\hline Parameter & $T_{0}$ & $T_{1}$ & $T_{2}$ & $T_{3}$ \\
\hline LVEDA $\left(\mathrm{cm}^{2}\right)$ & $19.7 \pm 1.7$ & $12 \pm 1.3^{*}$ & $11.8 \pm 1.16^{*}$ & $20.2 \pm 2.42$ \\
LVESA $\left(\mathrm{cm}^{2}\right)$ & $8.4 \pm 0.37$ & $5.8 \pm 0.68^{\bullet}$ & $5.9 \pm 0.49^{\bullet}$ & $3.8 \pm 0.47$ \\
LVEDP $(\mathrm{mmHg})$ & $10.4 \pm 3.3$ & $3.8 \pm 1.6^{*}$ & $49.6 \pm 3.5^{\star}$ & $11 \pm 1.8$ \\
FAC $(\%)$ & $57.2 \pm 3.5$ & $51.2 \pm 5.2$ & $3.1 \pm 0.76^{*}$ & $56.6 \pm 3$ \\
CO $(\mathrm{L} / \mathrm{min})$ & $4.9 \pm 0.48$ & $3.5 \pm 0.61^{*}$ & $2.05 \pm 0.36^{*}$ & $5.3 \pm 0.66$ \\
CI $\left(\mathrm{L} \mathrm{min}\right.$ m $\left.^{-1}\right)$ & $3.2 \pm 0.23$ & $2.3 \pm 0.73^{*}$ & $2.8 \pm 1.9^{*}$ & $3.4 \pm 0.26$ \\
CVP $\left(\mathrm{mmHg}^{*}\right.$ & $9.4 \pm 3$ & $2.6 \pm 1.6^{*}$ & $8.8 \pm 1.8$ \\
\hline
\end{tabular}

Data are presented as means \pm SD; Left Ventricular End-Diastolic Area (LVEDA), Left Ventricular End-Systolic Area (LVESA), Left Ventricular End-Diastolic Pressure (LVEDP), Fractional Area Contraction (FAC), Cardiac Output (CO), Cardiac Index (CI), Central Venous Pressure $(\mathrm{CVP})$. ( ${ }^{*} P<0.001$ versus $T_{0}$; $\bullet P \leq 0.05$ versus $T_{0} ;{ }^{\triangle} P=0.014$ versus $\left.T_{0}\right)$.

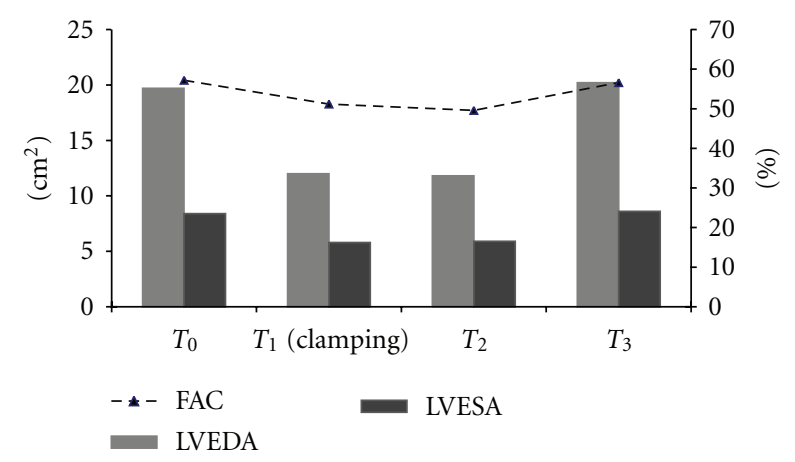

Figure 1: Changes of $\operatorname{LVEDA}_{(\mathrm{TEE})}$, LVESA(TEE), and FAC $(\mathrm{TEE})$ before HVE (T0), during HVE $\left(T_{1}-T_{2}\right)$ and after unclamping (T3).

\section{Discussion}

Continuous collaboration between the anaesthesiologists and the surgeons is required for the success of a liver resection. The principle is even more important in achieving low Central Venous Pressure (CVP), which currently represents the gold standard in minimizing blood loss during parenchymal resection. The pressure within the liver from the hepatic veins to sinusoids is directly related to the pressure in the IVC, which is directly dependant on the CVP. The hypothesis that low CVP would be accompanied by a low pressure in the hepatic veins and thereby decreasing blood loss during resection has been tested in several studies after having been evoked in clinical practice for the first time in the early nineties [2]. It is probable that a reduction in blood loss and blood transfusion requirements can be

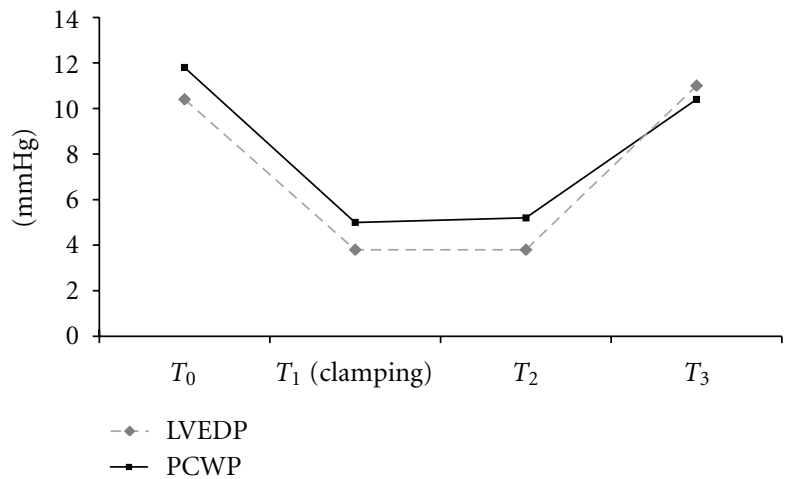

FIGURE 2: Hemodynamic effects of hepatic vascular exclusion and unclamping on Pulmonary Capillary Wedge Pressure $\left(\mathrm{PCWP}_{(\mathrm{PAC}}\right)$, and Left Ventricular End-Diastolic Pressure $\left(\operatorname{LVEDP}_{(\mathrm{TEE})}\right)$.

achieved if the CVP is maintained below $5 \mathrm{~cm} \mathrm{H}_{2} \mathrm{O}$ during parenchymal resection. Therefore cardiovascular monitoring is an invaluable intraoperative aid to surgical decisionmaking and quality assurance of the resection. TEE is a valid alternative to invasive monitoring like pulmonary artery catheter. Previously this method has been successfully used during cardiac surgery, especially during cardiac valve repair [3].

The results of this study confirm previous data on intraoperative TEE though caution should be used in interpreting the results because the sample population was very small. This method may provide a reliable assessment of hemodynamic parameters and improve the management of patients at high cardiovascular risk undergoing 
TABLE 4: Parameters measured by PAC during hepatic vascular exclusion $(n=5)$.

\begin{tabular}{lcccc}
\hline Parameter & $T_{0}$ & $T_{1}$ & $T_{2}$ & $T_{3}$ \\
\hline CVP $(\mathrm{mmHg})$ & $8.6 \pm 2.4$ & $3 \pm 1.2^{*}$ & $3.2 \pm 1.3^{*}$ & $8.8 \pm 1.9$ \\
PCWP $(\mathrm{mmHg})$ & $11.8 \pm 2.1$ & $5 \pm 1^{*}$ & $5.2 \pm 1.3^{*}$ & $10.4 \pm 1.5$ \\
CO $(\mathrm{L} / \mathrm{min})$ & $4.8 \pm 0.63$ & $3.7 \pm 0.52^{*}$ & $3.1 \pm 0.6^{*}$ & $5.26 \pm 0.73$ \\
CI $\left(\mathrm{L} \mathrm{min}\right.$ m $\left.^{-1} \mathrm{~m}^{-2}\right)$ & $3.16 \pm 0.29$ & $2.5 \pm 0.63^{*}$ & $2 \pm 0.34^{*}$ & $3.4 \pm 0.29$ \\
SVR $\left(\right.$ dyne s$\left.^{-1} \mathrm{~cm}^{-5}\right)$ & $1209 \pm 258$ & $1556 \pm 323.4^{\circ}$ & $1795 \pm 462^{\circ}$ & $950 \pm 152^{\circ}$ \\
\hline
\end{tabular}

Data are presented as means \pm SD; Stroke Volume (SV), Central Venous Pressure (CVP), Pulmonary Capillary Wedge Pressure (PCWP), Cardiac Output (CO), Cardiac Index (CI), Systemic Vascular Resistance (SVR) ( ${ }^{*} P<0.001$ versus $T_{0} ;{ }^{\circ} P=0.004$ versus $T_{0}$ ).

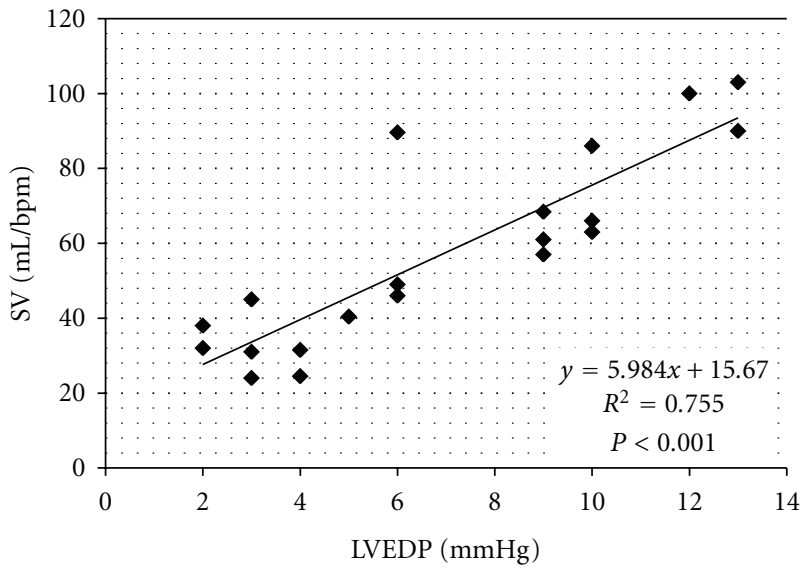

FIGURE 3: Linear correlation analysis of the relationship between stroke volume (SV) and Left Ventricular End-Diastolic Pressure $\left(\operatorname{LVEDP}_{(\mathrm{TEE})}\right)$.

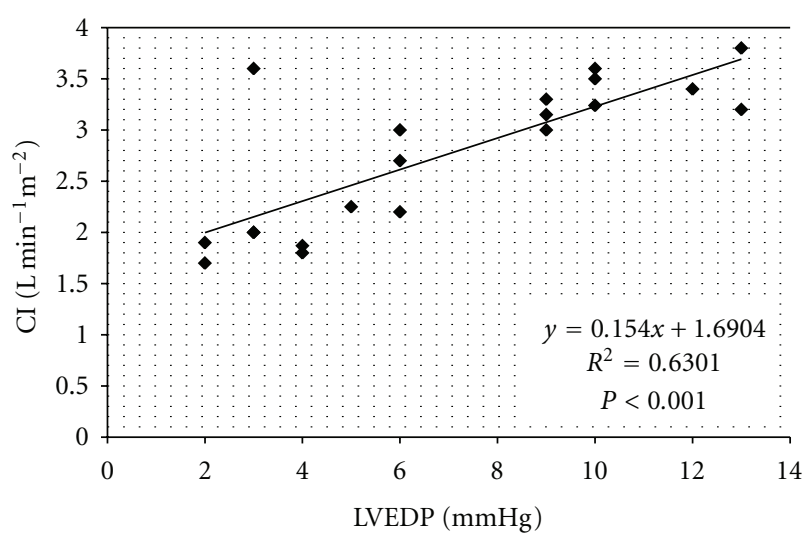

FIGURE 4: Linear correlation analysis of the relationship between cardiac index $\left(\mathrm{CI}_{(\mathrm{TEE})}\right)$ and Left Ventricular End-Diastolic Pressure $\left(\operatorname{LVEDP}_{(\mathrm{TEE})}\right)$.

noncardiac surgery, including abdominal surgery [4, 5]. Perioperative left ventricular preload should be optimized in order to obtain an adequate cardiac performance. TEE, by estimating LVEDA, may provide an indirect assessment of left ventricular preload. The results of this study suggest that LVEDA and LVEDP measured by TEE may provide a reliable information about preload conditions. In particular, LVEDP appears more related to SV changes than LVEDA.
An accurate evaluation of LV filling pressures may increase the diagnostic value of TEE for routine assessment in anesthetised, ventilated patients. The results of this study indicate that TEE may provide additional information compared to pulmonary artery catheterization in the assessment of preload in patients undergoing HVE. In previous studies, LVEDA from the transgastric mid-papillary short axis view, has been used as the only measure of preload in vascular and cardiac surgery $[6,7]$. This parameter has been previously assessed also in critically ill patients $[8,9]$. Numerous studies have shown that LVEDA correlates with SV changes [1014]. This latter is a good predictor of the response to fluids administration [15]. The results of our observation are clinically relevant because undetected hypovolemia is a common event during major surgery. Hypovolemia, on the other hand, may impair tissue perfusion, decrease oxygen delivery, and increase postoperative complications [16].

Major hepatic surgery is associated to specific problems concerning volemia and preload: vascular exclusion, indeed, by decreasing venous return, causes a relative hypovolemia; this condition is generally favourable during surgery as it minimizes intraoperative bleeding and the need for blood transfusion $[17,18]$. The indices of cardiac filling (LVEDP and LVEDA) evaluated by TEE in the present study have been correlated to PCWP, as assessed by PAC. The time course of both parameters was super imposable, as a likely consequence of the fact that our selected patients were free from major cardiovascular and respiratory diseases, in fact no patients required supplemental noninvasive stress testing (dobutamine stress echocardiography). PCWP is generally used as a marker of left atrial pressure; this parameter, however, is no more a reliable predictor of ventricular filling and of the efficacy of fluids replacement in patients artificially ventilated [19]. Transesophageal echocardiography, on the other hand, may provide a reliable measurement of left ventricular filling pressure also in patients artificially ventilated [20]. This method, by providing the measurement of several parameters with a good correlation with PCWP, is a valid alternative to cardiac catheterization, a procedure not devoid of major complications $[21,22]$. The PiCCO system may also provide a reliable information about left ventricular preload and efficacy of volume replacement without the risks of pulmonary catheterization; unfortunately, this method has not been tested in the present study as an alternative to transesophageal doppler due to the specific conditions related to hepatic surgical resection $[23,24]$. These conditions, potentially causing hemodynamic 
instability, include right ventricular insufficiency, myocardial ischemia, pulmonary thromboembolism in the reperfusion phase, and after hepatic unclamping, paradoxical embolism in the presence of a patent oval foramen. Transesophageal echocardiography by rapidly identifying these complications may provide an immediate treatment [5].

In conclusion, the present study confirms published data on hemodynamic changes during hepatic vascular exclusion; our data support transesophageal echocardiography as a reliable approach for the intraoperative assessment of preload, via the measurement of LVEDP and LVEDA. The time course of LVEDP changes was super imposable to that of LVEDA and PCWP in patients with preserved cardiac function; the significant correlation between LVEDP and SV changes supports the view that transesophageal echocardiography should be more extensively applied for non invasive hemodynamic monitoring in patients undergoing major noncardiac surgery. However, TEE could be subjective and is affected by training, experience, and skills of operator. Therefore intraoperative TEE, during major liver resection, is valuable to diagnose cardiovascular complications, to guide surgical treatment, especially during HVE. Intraoperative TEE allowed our operative team to choose the best surgical approach, to evaluate the haemodynamic modifications produced by HVE, and to modify surgical techniques based on real-time data to achieve an optimal outcome.

\section{Conflict of Interests}

The authors have no conflict of interests to declare.

\section{Acknowledgments}

The authors would like to thank Anna Venturato for her assistance in preparing the paper. No financial support was received to perform this clinical observation.

\section{References}

[1] D. Eyraud, O. Richard, D. C. Borie et al., "Hemodynamic and hormonal responses to the sudden interruption of caval flow: insights from a prospective study of hepatic vascular exclusion during major liver resections," Anesthesia and Analgesia, vol. 95, no. 5, pp. 1173-1178, 2002.

[2] L. H. Blumgart, H. U. Baer, A. Czerniak, A. Zimmermann, and A. R. Dennison, "Extended left hepatectomy: technical aspects of an evolving procedure," British Journal of Surgery, vol. 80, no. 7, pp. 903-906, 1993.

[3] Y. G. Peng, T. Martin, T. Horowitz, A. Sidi, and G. Janelle, "Repair of concomitant valvular endocarditis using a single homograft," Annals of Thoracic Surgery, vol. 88, no. 2, pp. e14e15, 2009.

[4] M. C. Schulmeyer Cabrera, E. Santelices, R. Vega, and S. Schmied, "Impact of intraoperative transesophageal echocardiography during non cardiac surgery," Journal of Cardiothoracic and Vascular Anesthesia, vol. 20, no. 6, pp. 768-771, 2006.

[5] E. Catena and D. Mele, "Role of intraoperative transesophageal echocardiography in patients undergoing noncardiac surgery," Journal of Cardiovascular Medicine, vol. 9, no. 10, pp. 993-1003, 2008.
[6] P. Coriat, M. Vrillon, A. Perel et al., "A comparison of systolic blood pressure variations and echocardiographic estimates of end-diastolic left ventricular size in patients after aortic surgery," Anesthesia and Analgesia, vol. 78, no. 1, pp. 46-53, 1994.

[7] J. M. Leung and E. H. Levine, "Left ventricular end-systolic cavity obliteration as an estimate of intraoperative hypovolemia," Anesthesiology, vol. 81, no. 5, pp. 1102-1109, 1994.

[8] O. Axler, C. Tousignant, C. R. Thompson et al., "Small hemodynamic effect of typical rapid volume infusions in critically ill patients," Critical Care Medicine, vol. 25, no. 6, pp. 965-970, 1997.

[9] J. M. Vedrinne, S. Duperret, F. Decaillot, P. Gratadour, and J. Motin, "Haemodynamic changes induced by two I:E ratios: a transoesophageal echocardiographic study," Canadian Journal of Anaesthesia, vol. 44, no. 4, pp. 354-359, 1997.

[10] A. T. Cheung, J. S. Savino, S. J. Weiss, S. J. Aukburg, and J. A. Berlin, "Echocardiographic and hemodynamic indexes of left ventricular preload in patients with normal and abnormal ventricular function," Anesthesiology, vol. 81, no. 2, pp. 376387, 1994.

[11] D. L. Reich, S. N. Konstadt, M. Nejat, H. P. Abrams, and J. Bucek, "Intraoperative transesophageal echocardiography for the detection of cardiac preload changes induced by transfusion and phlebotomy in pediatric patients," Anesthesiology, vol. 79, no. 1, pp. 10-15, 1993.

[12] W. Buhre, K. Buhre, S. Kazmaier, H. Sonntag, and A. Weyland, "Assessment of cardiac preload by indicator diluition and transesophageal echocardiography," European Journal of Anaesthesiology, vol. 18, pp. 662-667, 2001.

[13] C. A. Greim, N. Roewer, C. Apfel, G. Laux, and J. Schulte Am Esch, "Relation of echocardiographic preload indices to stroke volume in critically ill patients with normal and low cardiac index," Intensive Care Medicine, vol. 23, no. 4, pp. 411-416, 1997.

[14] K. Scheuren, M. N. Wente', C. Hainer et al., "Left ventricular end-diastolic area is a measure of cardiac preload in patients with early septic shock," European Journal of Anaesthesiology, vol. 26, no. 9, pp. 759-765, 2009.

[15] S. Preisman, S. Kogan, H. Berkenstadt, and A. Perel, "Predicting fluid responsiveness in patients undergoing cardiac surgery: functional haemodynamic parameters including the Respiratory Systolic Variation Test and static preload indicators," British Journal of Anaesthesia, vol. 95, no. 6, pp. 746-755, 2005.

[16] S. M. Abbas and A. G. Hill, "Systematic review of the literature for the use of oesophageal Doppler monitor for fluid replacement in major abdominal surgery," Anaesthesia, vol. 63, no. 1, pp. 44-51, 2008.

[17] W. D. Wang, L. J. Liang, X. Q. Huang, and X. Y. Yin, "Low central venous pressure reduces blood loss in hepatectomy," World Journal of Gastroenterology, vol. 12, no. 6, pp. 935-939, 2006.

[18] J. A. Melendez, V. Arslan, M. E. Fischer et al., "Perioperative outcomes of major hepatic resections under low central venous pressure anesthesia: blood loss, blood transfusion, and the risk of postoperative renal dysfunction," Journal of the American College of Surgeons, vol. 187, no. 6, pp. 620-625, 1998.

[19] K. Bendjelid and J. A. Romand, "Fluid responsiveness in mechanically ventilated patients: a review of indices used in intensive care," Intensive Care Medicine, vol. 29, no. 3, pp. 352$360,2003$. 
[20] P. Vignon, A. AitHssain, B. François et al., "Echocardiographic assessment of pulmonary artery occlusion pressure in ventilated patients: a transoesophageal study," Critical Care, vol. 12, no. 1, article R18, 2008.

[21] G. Voga, "Pulmonary artery occlusion pressure estimation by transesophageal echocardiography: is simpler better?" Critical Care, vol. 12, no. 2, article 127, 2008.

[22] Y. Ohnishi, "Pulmonary artery catheter-its utility and limitations," Japanese Journal of Anesthesiology, vol. 58, no. 7, pp. 884-890, 2009.

[23] C. K. Hofer, M. T. Ganter, S. Matter-Ensner et al., "Volumetric assessment of left heart preload by thermodilution: comparing the PiCCO-VoLEF system with transoesophageal echocardiography," Anaesthesia, vol. 61, no. 4, pp. 316-321, 2006.

[24] D. R. Chittock, V. K. Dhingra, J. J. Ronco et al., "Severity of illness and risk of death associated with pulmonary artery catheter use," Critical Care Medicine, vol. 32, no. 4, pp. 911915, 2004. 


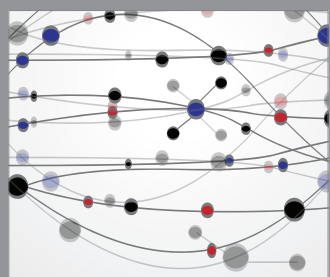

The Scientific World Journal
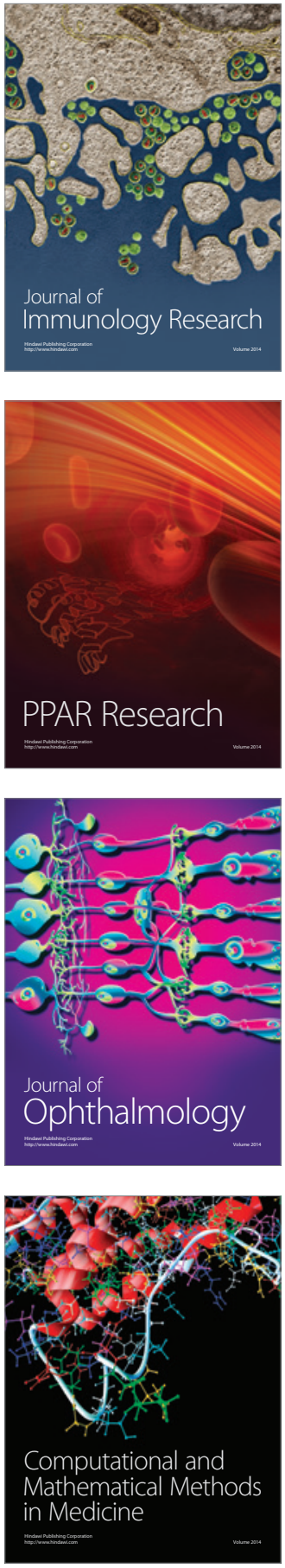

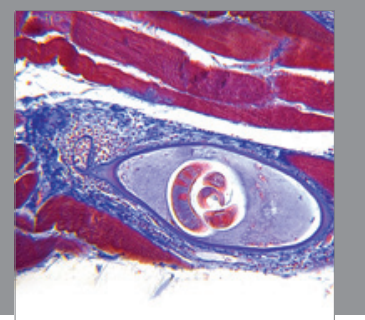

Gastroenterology

Research and Practice
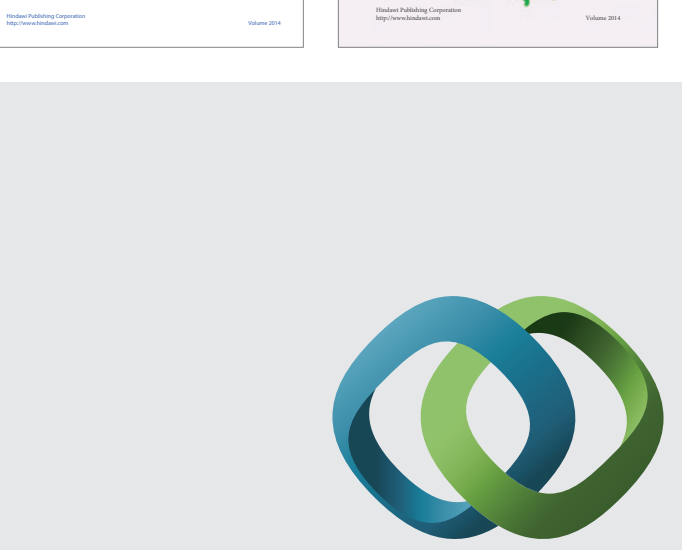

\section{Hindawi}

Submit your manuscripts at

http://www.hindawi.com
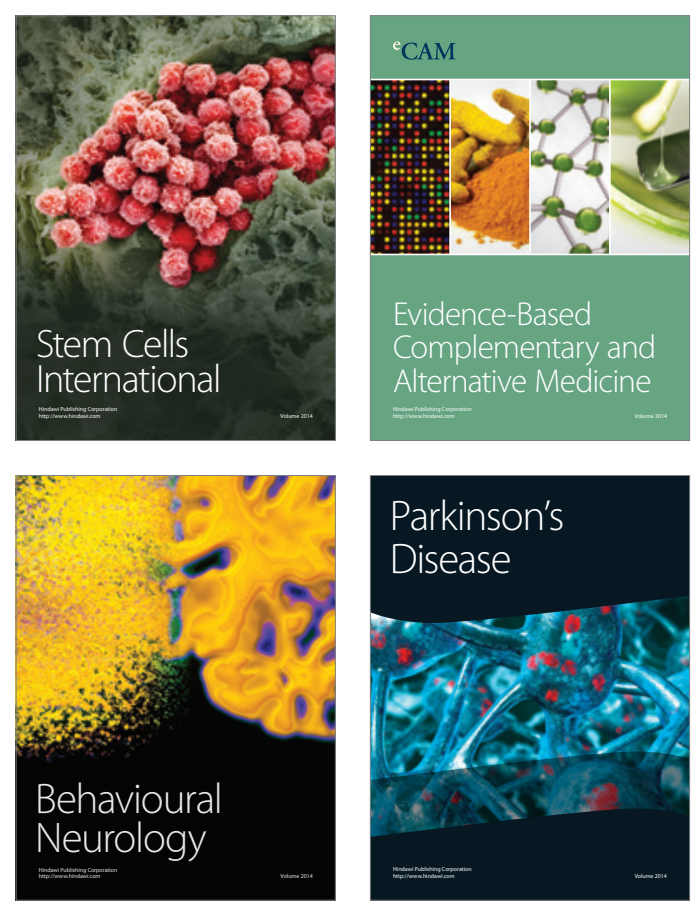

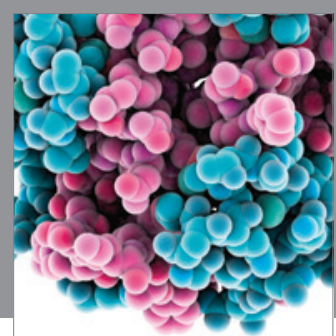

Journal of
Diabetes Research

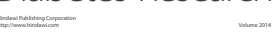

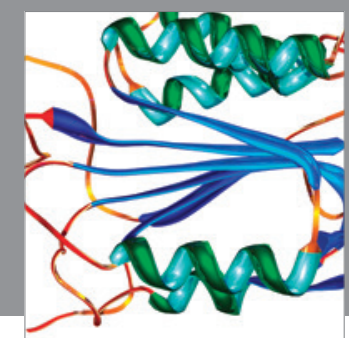

Disease Markers
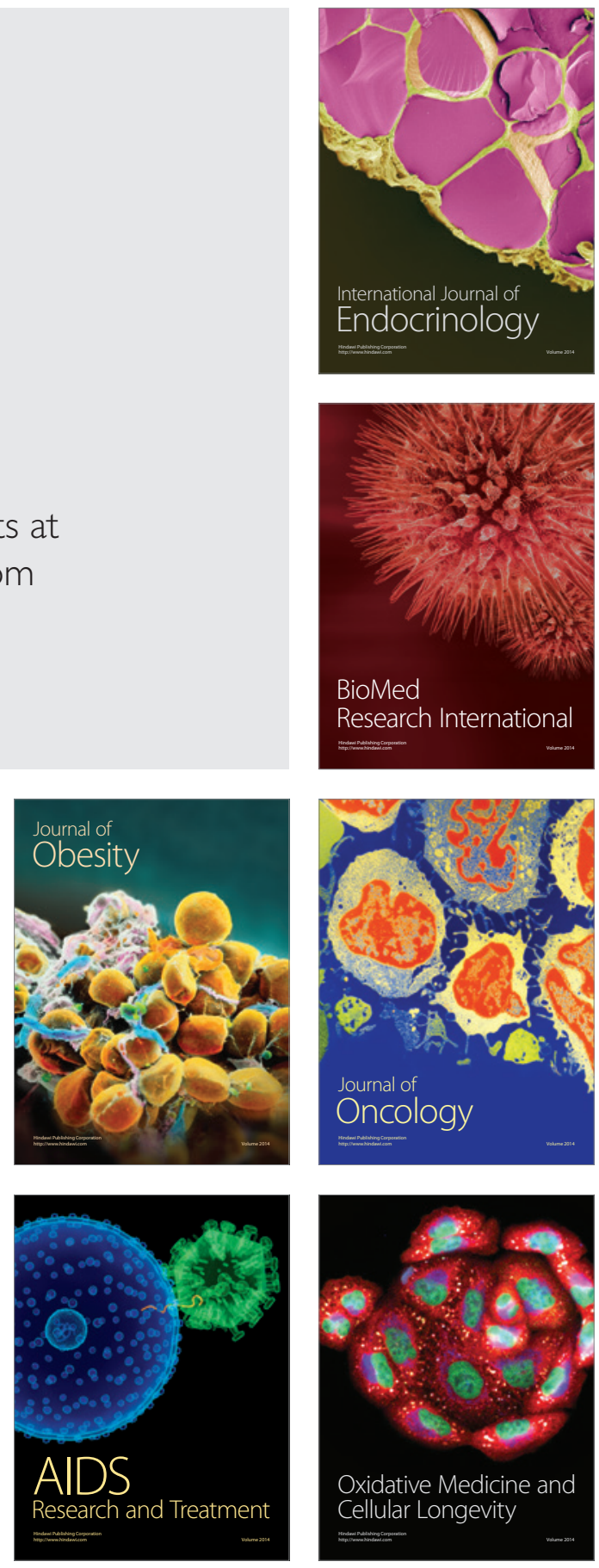